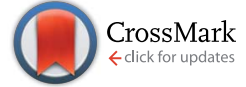

Cite this: RSC Adv., 2017, 7, 6215

\title{
Reply to the 'Comments on "Dental lessons from past to present: ultrastructure and composition of teeth from plesiosaurs, dinosaurs, extinct and recent sharks"' by H. Botella et al., RSC Adv., 2016, $6,74384-74388 \dagger$
}

\author{
A. Luebke, ${ }^{a}$ K. Loza, ${ }^{a}$ R. Patnaik, ${ }^{\text {b }}$ J. Enax, ${ }^{a}$ D. Raabe, ${ }^{c}$ O. Prymak, $^{a}$ H.-O. Fabritius, ${ }^{c}$ \\ P. Gaengler ${ }^{d}$ and M. Epple ${ }^{\star a}$
}

The structure and composition of 13 fossilized tooth and bone samples aged between 3 and 70 million years were analysed. It was found that they all contained high amounts of fluoroapatite. This indicates that originally present hydroxyapatite had been converted to fluoroapatite during the diagenesis. Thus, the chemical analysis allows no conclusion with respect to the original composition of our fossil samples. Our results indicate that the diagenetic transformation of hydroxyapatite into fluoroapatite is at least partially dependent on microstructural characteristics of the original tissue such as the degree of porosity.

Received 21st November 2016 Accepted 2nd January 2017

DOI: 10.1039/c6ra27121a

www.rsc.org/advances changes that caused unfavourable conditions for the use of fluoroapatite as tooth mineral.

However, it has been brought to our attention and commented in a recent publication, ${ }^{\mathbf{1 1}}$ that the diagenetic conversion of hydroxyapatite to fluoroapatite is a common feature during fossilization (see ref. 12-14 and also the article by de Renzi et al. ${ }^{11}$ ). This means that no conclusion is possible for fossil samples with respect to their original fluoride content. Following this criticism, we have analysed further fossil samples of different origin with respect to their ultrastructure, their mineral composition, and their fluoride content. Our new results show that the fluorine content of fossil teeth and bones increases with age during the course of fossilization due to the diagenetic transformation of hydroxyapatite to the more stable fluoroapatite.

\section{Experimental}

\section{Materials}

All fossil teeth and bones were found, determined, and provided by R. Patnaik. The dinosaur bone sample came from calcareous sandy limestone of the Late Cretaceous Lameta Formation. These rocks are exposed in central India lying stratigraphically below geochronologically dated $\sim 65$ Ma old Deccan Basalts. Biostratigraphically dated Eocene Subathu Formation pseudoconglomerates exposed in the $\mathrm{N}-\mathrm{W}$ Lesser Himalayas have yielded the artiodactyl raoellids. The Miocene shallow marine shark/ray/crocodile-yielding limestone deposits in the west (Kutch) and east (Baripada) have been tentatively dated using mammalian biostratigraphy (see ref. 15 and references therein). The snakehead fish and crocodile remains derived from the 

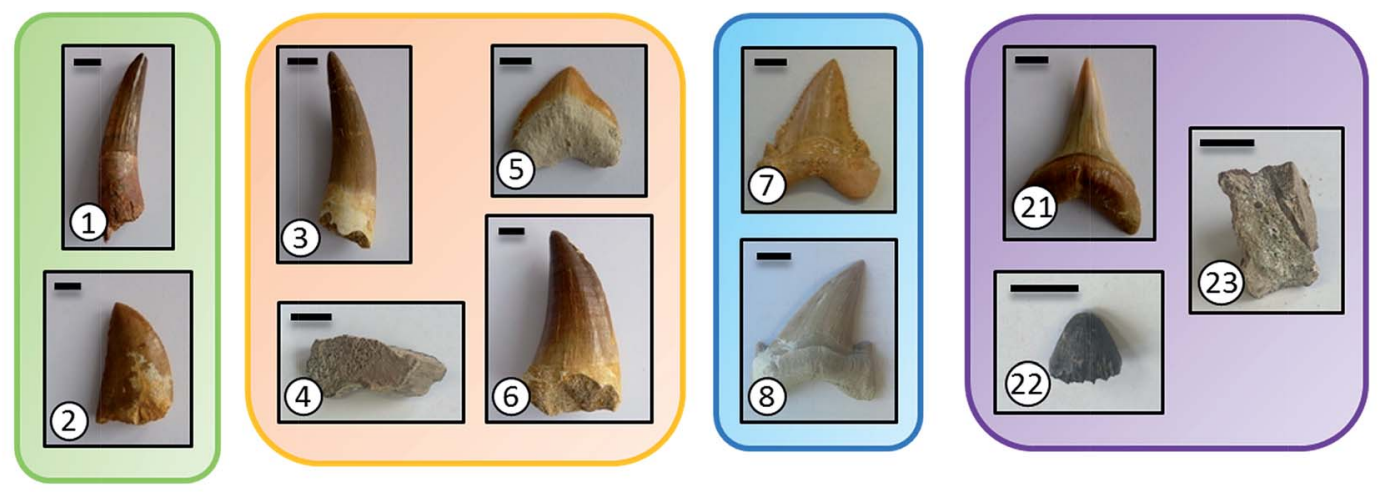

\begin{tabular}{c|c|c|c|c|c|c|c|c}
\hline \multicolumn{2}{c|}{ Cretaceous } & \multicolumn{3}{c|}{ Palaeogene } & \multicolumn{2}{c}{ Neogene } \\
Early Cretaceous & Late Cretaceous & Palaeocene & Eocene & Oligocene & Miocene & Pliocene & Pleistocene & Holocene \\
\hline $146-100$ & $100-66$ & $66-56$ & $56-34$ & $35-23$ & $23-5.3$ & $5.3-2.5$ & $2.5-1$ & $1-0$ \\
\hline
\end{tabular}
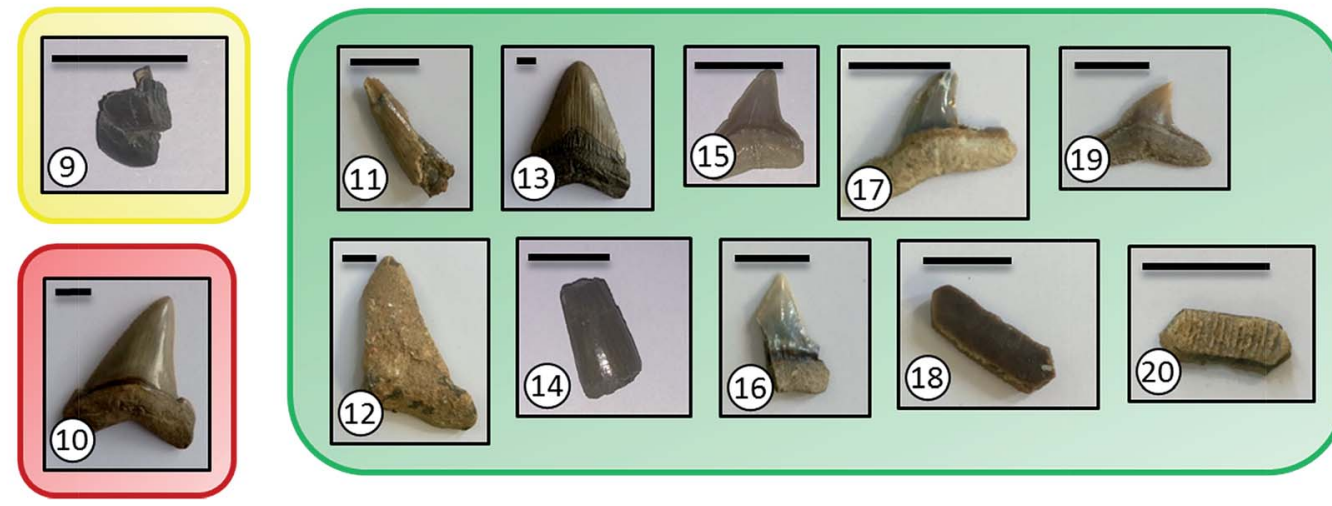

Fig. 1 Images of all investigated fossil specimens (see Table 1 for the individual species names and sample codes). The scale bar is $1 \mathrm{~cm}$ in all images.

Siwalik paleosols (Devni Khadri and Moginand) were dated using small mammal biozonation. Images of all samples are given in Fig. 1. All information like age, location, and stratigraphy is summarized in Table 1 .

\section{Instruments}

Bone samples were freeze-fractured and analysed in full with no special separation of the parts. Teeth samples were separated into the individual tissues (dentin, enamel, enameloid) as described in the following. Except for this different separation, treatment, preparation, and analyses of bone and teeth were identical.

Scanning electron microscopy (SEM) was used to visualize the internal structure of enameloid, enamel, dentin, and the dentin-enameloid-junction.

For axial freeze fracture, the teeth were immersed into liquid nitrogen for $2 \mathrm{~min}$ and mechanically broken into two pieces. Secondary electron (SE) microscopy and qualitative energydispersive X-ray spectroscopy (EDX) were carried out with an ESEM Quanta 400 FEG instrument after sputtering with gold and palladium $(80: 20)$.

To determine the chemical composition and the differences between enameloid, enamel, and dentin with respect to crystallinity and crystallite size, X-ray powder diffraction (XRD) was used. For this, the samples were ground into a fine powder as follows: the teeth were transversely cut using a Proxxon FBS 230/E fine drilling and polishing tool equipped with a diamondcoated cutting disk. Fine powders of enameloid, enamel, or dentin, respectively (a few $\mathrm{mg}$ per sample), were obtained from corresponding areas of the cut teeth with the same instrument using a diamond-coated drill. This powder was used for X-ray diffraction and elemental analysis.

X-ray powder diffraction was carried out with a Bruker D8 Advance diffractometer ( $\mathrm{Cu} \mathrm{K} \alpha$ radiation, $\lambda=1.54 \AA$ ), using a silicon single crystal sample holder to minimize background scattering. Rietveld refinement for the calculation of the lattice parameters and the crystallite sizes was performed with the Bruker software TOPAS 4.2. For each Rietveld refinement, the instrumental correction was included as determined with a standard powder sample $\mathrm{LaB}_{6}$ (from NIST, National Institute of Standards and Technology, as standard reference material, SRM 660b). The size of the crystallites was calculated with the Scherrer equation after correction for instrumental peak broadening. ${ }^{16}$

The $a$-axis of the enameloid and of the geological fluoroapatite single crystal was shorter than in synthetic hydroxyapatite. We have estimated the fluoride content using the 
Table 1 Samples investigated, including the teeth from our previous publication (indicated by an asterisk after the sample code number) ${ }^{10}$

\begin{tabular}{|c|c|c|c|c|c|c|}
\hline \# & Taxa & Group & Stratigraphy & Location & $\begin{array}{l}\text { Sample } \\
\text { kind }\end{array}$ & Age/Ma \\
\hline $1^{*}$ & Spinosaurus maroccanus & Dinosaur & Early Cretaceous & Oued-Zem, Morocco & Tooth & $\sim 110$ \\
\hline $3 *$ & Plesiosaurus mauritanicus & Plesiosaur & Late Cretaceous & Oued-Zem, Morocco & Tooth & $\sim 70$ \\
\hline 4 & Most likely Sauropod dinosaur & Dinosaur & $\begin{array}{l}\text { Late Cretaceous, } \\
\text { Lameta Formation }\end{array}$ & Jabalpur, Madhya Pradesh & Bone & $\sim 70$ \\
\hline $7^{*}$ & Paleocarcharodon orientalis & Shark & Middle Palaeocene & Khouribga, Morocco & Tooth & $\sim 60$ \\
\hline $8^{*}$ & Otodus obliquus & Shark & Middle Palaeocene & Khouribga, Morocco & Tooth & $\sim 60$ \\
\hline 9 & Raoellid tooth fragment & Mammal & $\begin{array}{l}\text { Middle Eocene, } \\
\text { Subathu Formation }\end{array}$ & $\begin{array}{l}\text { Kalakot, Jammu and } \\
\text { Kashmir, India }\end{array}$ & Tooth & $\sim 40$ \\
\hline $10^{*}$ & Carcharocles angustidens & Shark & Oligocene & South Carolina, USA & Tooth & $\sim 28$ \\
\hline 11 & Tomistoma sp. & Crocodile & $\begin{array}{l}\text { Early Miocene, } \\
\text { Khari Nadi Formation }\end{array}$ & Kutch, Gujarat, India & Tooth & $\sim 16$ \\
\hline 14 & Gavialis sp. & Crocodile & Late Pliocene, Tatrot formation & Devni Khadri, India & Tooth & $\sim 2.6$ \\
\hline 15 & Carcharinus sp. indet & Shark & Late Miocene, Baripada Beds & Baripada, Orissa, India & Tooth & $8-10$ \\
\hline 16 & Lamna sp. & Shark & Late Miocene, Baripada Beds & Baripada, Orissa, India & Tooth & $8-10$ \\
\hline 17 & Carcharinus sp. & Shark & Late Miocene, Baripada Beds & Baripada, Orissa, India & Tooth & $8-10$ \\
\hline 18 & Myliobatis sp. & Ray & Late Miocene, Baripada Beds & Baripada, Orissa, India & Tooth & $8-10$ \\
\hline 19 & Carcharinus perseus & Shark & Late Miocene, Baripada Beds & Baripada, Orissa, India & Tooth & $8-10$ \\
\hline 20 & Rhinoptera sp. & Ray & Late Miocene, Baripada Beds & Baripada, Orissa, India & Tooth & $8-10$ \\
\hline $21^{*}$ & Isurus hastalis & Shark & Early Pliocene & Copiapo, Chile & Tooth & $\sim 5$ \\
\hline 22 & Crocodylus sp. & Crocodile & Late Pliocene, Tatrot Formation & Devni Khadri, India & Tooth & $\sim 2.6-3$ \\
\hline 23 & Crocodylus sp. & Crocodile & Late Pliocene, Tatrot Formation & Devni Khadri, India & Bone & $\sim 2.6-3$ \\
\hline
\end{tabular}

correlation function given by LeGeros and Suga. ${ }^{5}$ As this method assumes that the content of foreign ions (e.g. $\mathrm{Na}, \mathrm{Mg}$, carbonate) is negligible, these fluoride contents are associated with a considerable error. In particular, the presence of carbonate in the apatite lattice also leads to a shortening of the $a$-axis, which results in systematically higher apparent fluoridecontents using the LeGeros/Suga method.

Elemental analysis was carried out to determine the overall chemical composition of the samples. For the determination of calcium with atomic absorption spectroscopy (AAS), fluoride with ion-selective potentiometry, and phosphate with ultraviolet (UV) spectroscopy, the powders were dissolved in concentrated ultrapure hydrochloric acid. Calcium was determined with a ThermoElectron, M-Series atomic absorption spectrometer. Phosphate was determined with a Varian Cary 300 UV-Vis spectrophotometer as phosphate-molybdenum blue complex. For fluoride analysis, ion-selective potentiometry was used (ionselective electrode, ISE; pH/ION 735, WTW; measurement performed by Analytische Laboratorien GmbH, Lindlar, Germany).

Thermogravimetry (TG) was used to determine the contents of water, organic matrix and carbonated apatite in the teeth. For TG analysis, the teeth were transversely cut. To obtain pure enamel or enameloid, we cut off the tip of the tooth for analysis. To obtain almost pure dentin, we used the lower part of the tooth where it met the root. Thermogravimetry was carried out with a Netzsch STA 449 F3 Jupiter instrument in dynamic oxygen atmosphere (heating rate $2 \mathrm{~K} \mathrm{~min}^{-1}$ from 25 to $1200^{\circ} \mathrm{C}$; open alumina crucibles).

\section{Results and discussion}

Fig. 1 shows images of all tooth and bone samples that we have investigated here, together with the tooth samples reported in our preceding publication. ${ }^{10}$ Table 1 gives all taxa, locations, and ages for the new samples. They represent a broad overview of species from a number of taxa that lived from 2.6 to about 100 million years ago. The dinosaur bone was found near Megaloolithus eggs that are considered as titanosaurid sauropods. The Eocene Raoellidae were amphibious hoofed mammals that are considered as close to ancestral whales. Tomistoma lived in the coastal areas and are closely related to crocodilids. Gavialis and Crocodylus are extant genera. The former preferred freshwater water bodies, whereas the latter liked marine conditions. The eagle ray Myliobatis and the cownose ray Rhinoptera preferred shallow marine conditions. Channa sp. is a freshwater carnivorous fish known since the Miocene. The glorious shark Megaselachus chubutensis is considered to be related to the megatoothed Carcharocles megalodon and Carcharocles angustidens. The mako shark Isurus and the mackerel shark Lamna belong to the family Lamnidae. The bull shark Carcharinus had a wide distribution, including freshwater conditions.

The full results of the chemical and crystallographic composition of the samples are given in Table 2. All samples consist of apatite as calcium phosphate mineral and contain variable amounts of calcium carbonate and quartz due to diagenesis during fossilization. With respect to the fluoride content, all samples contain a considerable fraction of fluoride. 


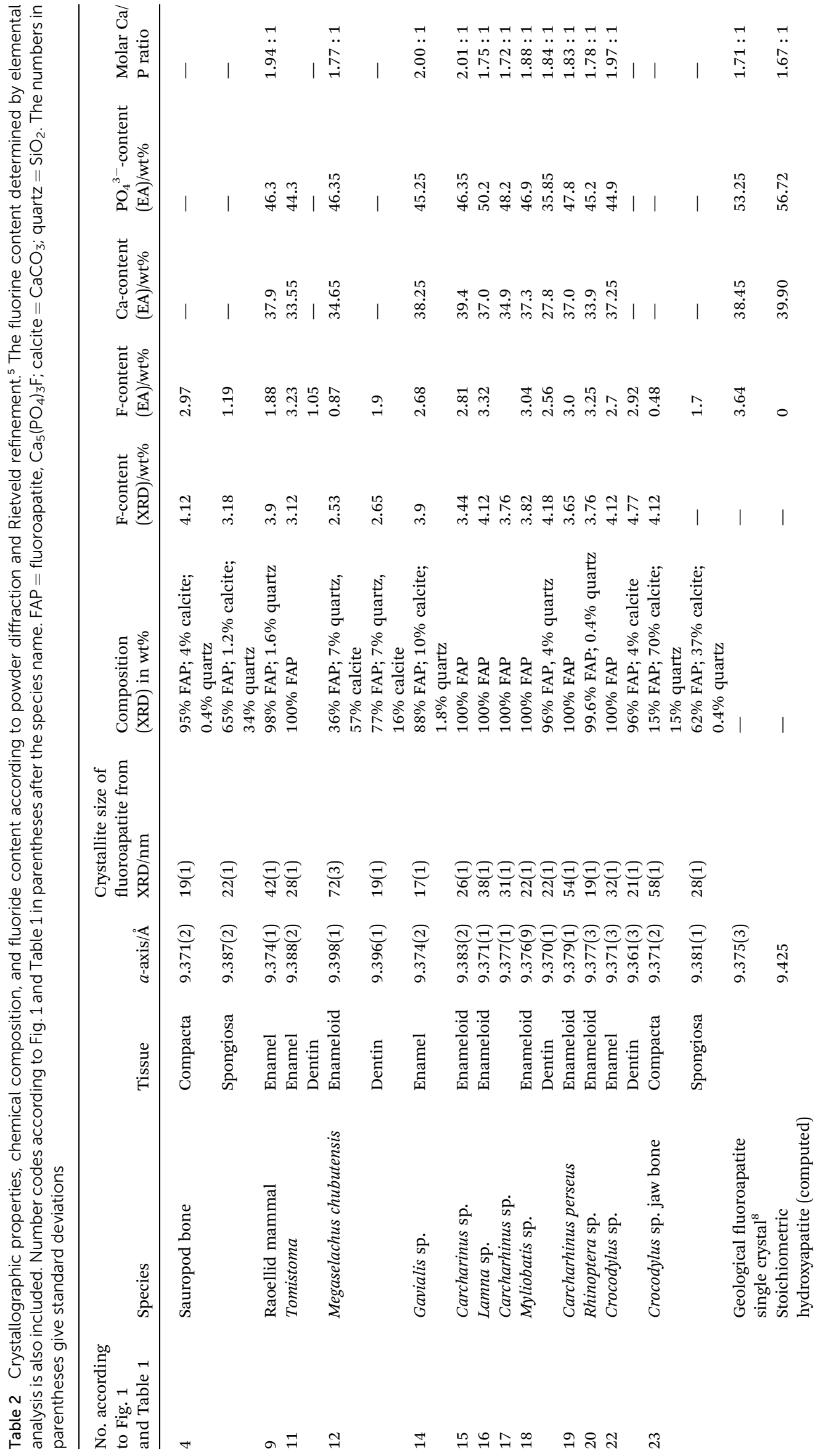


The fluoride content in enameloid and partially also in enamel and dentin is almost stoichiometric to fluoroapatite. Where possible, we have separated enamel (ectodermal origin), enameloid (dentin-like, mesectodermal origin) and dentin (mesectodermal origin), and separately analysed these phases.

Diagenesis of bones and teeth is a common phenomenon that is influenced by the composition of the enclosing sedimentary rock. The presence of groundwater facilitates this process by providing a medium for the ion exchange. During diagenesis, $\mathrm{pH}$ and Eh conditions of the surrounding environment play a major role in the precipitation of matrix-derived calcium and iron carbonates in the bone and teeth cavities. ${ }^{\mathbf{1 7}}$ Often, the biogenic apatite is replaced by francolite where $\mathrm{PO}_{4}{ }^{3-}$ is substituted by $\mathrm{CO}_{3}{ }^{2-}$ and $\mathrm{OH}^{-}$by $\mathrm{F}^{-} \cdot .^{\mathbf{1 4 , 1 8 - 2 0}}$ Fossil-bearing deposits that are exposed to ground water fluctuations undergo a diagenetic ion exchange leading to deposition of fluoride-bearing apatite. ${ }^{21}$ A recrystallization of francolite may introduce carbonate ions from groundwater in the bone cavities. $^{22}$

Fig. 2 shows the fluoride content in all analysed species as a function of age. As expected, the enameloid of sharks and rays contains almost stoichiometric amounts of fluoride. The values for the fossil taxa correspond well to those known for recent species, with a slight trend towards elevated fluoride contents with increasing age. This trend is much more pronounced in the dentin samples from sharks and rays. As the dentin of recent Chondrichthyes consists of hydroxyapatite, the fluorine must have entered the teeth from the surrounding sediments. This is most probably facilitated by the higher natural porosity of dentin in comparison to the very dense enameloid. The frequently observed presence of small crystallites with various shapes within the dentin tubuli of the fossil samples supports this.

While all our tooth and bone samples from fossil dinosaurs, plesiosaurs, mosasaurs, crocodiles, bony fish and mammals contain elevated amounts of fluorine, there is no obvious correlation between fluorine content and sample age.

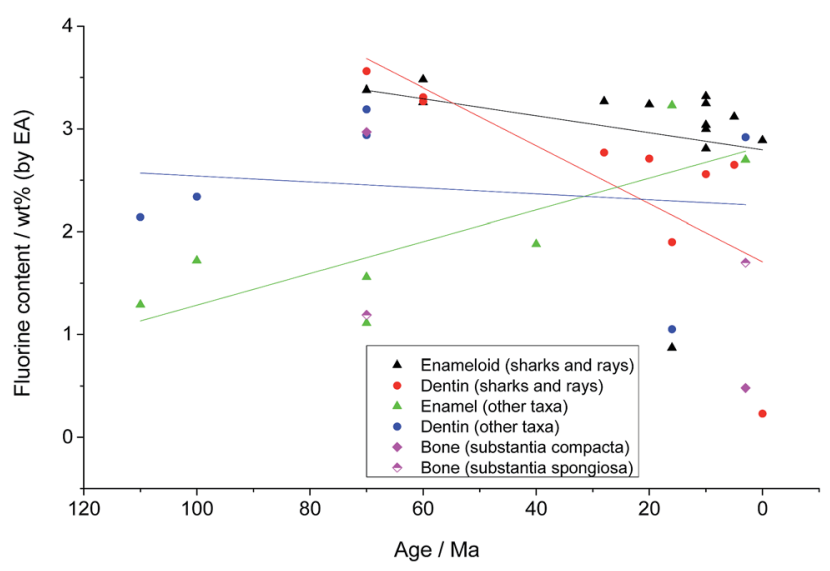

Fig. 2 Fluorine content (according to elemental analysis) versus the age of the investigated specimen. The results are pooled by tissue type, and Chondrichthyes are separated from the other taxa. The straight lines represent linear fits of data groups with corresponding colours to guide the eye for trends in the data. They are not meant to indicate a strict mathematical correlation.
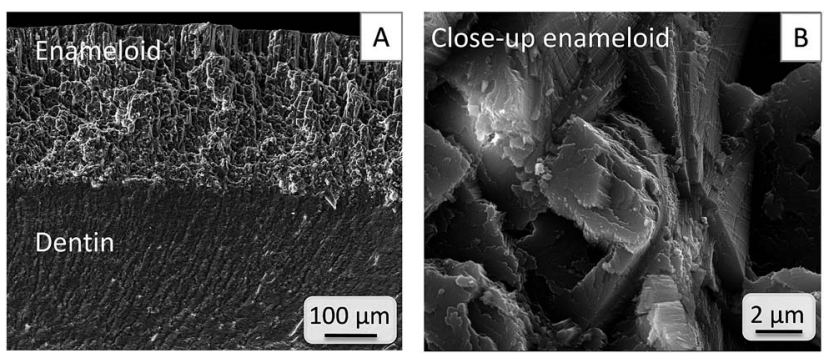

Fig. 3 SEM-images of a tooth of Carcharinus, 10 million years old (sample 15, Table 1). The enameloid-dentin junction is well visible (A), together with the well-preserved enameloid ultrastructure (B).

Nevertheless, given the different age, taxa, and location of all samples it is highly unlikely that the fluoride was present at the time of the death of the organism. It must have entered the samples during fossilization by fluoride uptake from the surrounding sediments.

Besides the changed chemical composition, the overall structure of the samples was remarkably well preserved. However, at higher magnifications we frequently observed structures that can be interpreted as diagenesis artefacts, such as small, odd-shaped crystallites within shark tooth enameloid (Fig. 3B) or the small pointy crystallites in the sauropod bone (Fig. 9B-D) which are not present in samples from recent relatives. This is an observation that we have already briefly reported in our preceding publication. ${ }^{10}$ In the following, we show some representative examples. The complete results can be found in the ESI. $\dagger$

Fig. 3 shows SEM images of a fossilized shark tooth where enameloid, dentin and the enameloid-dentin junction have a well-preserved original morphology. The ultrastructure resembles that of recent shark teeth with the typical fluoroapatite crystallite bundles. ${ }^{\mathbf{8 9}}$ However, larger crystallites with

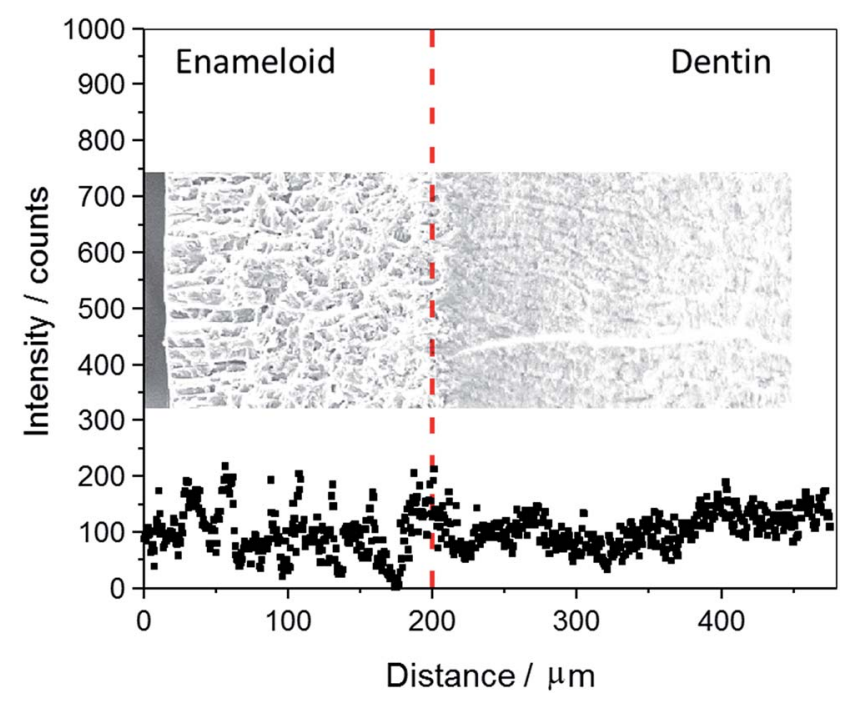

Fig. 4 EDX line-scan of fluorine across the enameloid (left site) into the dentin (right site) of a tooth of Carcharinus (sample 15, Table 1). The fluorine is homogeneously distributed across the tooth. 

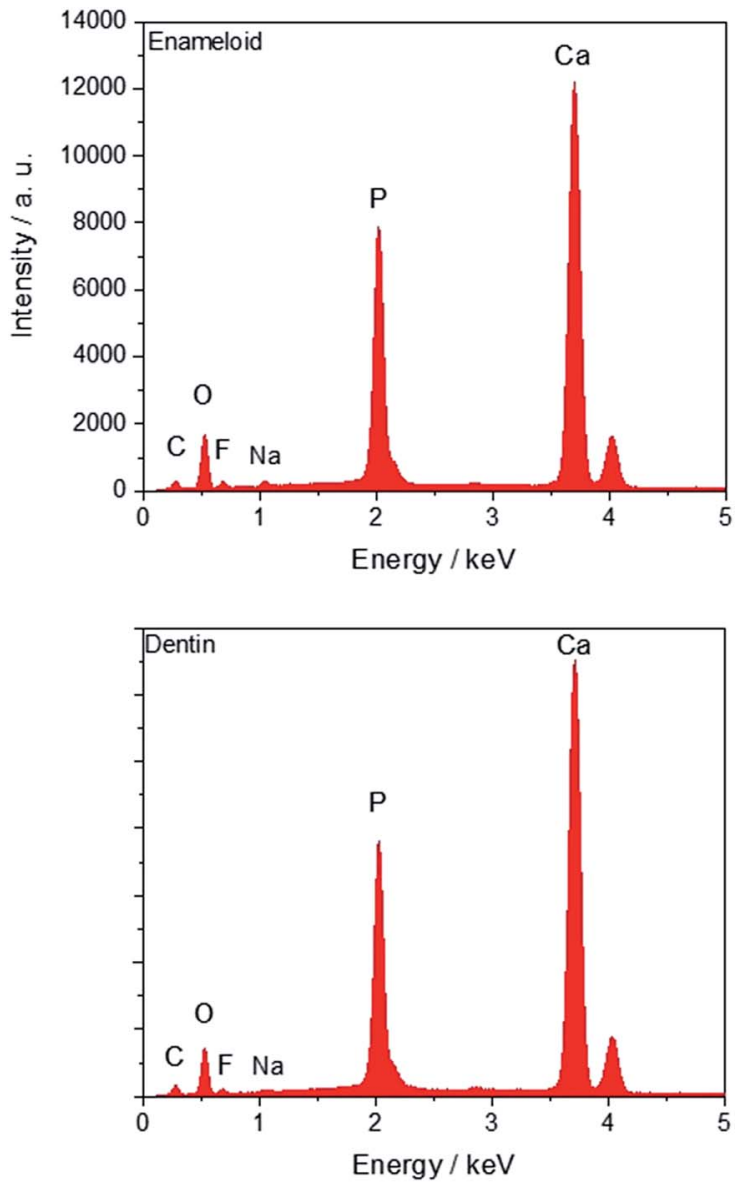

Fig. 5 EDX spectra of a tooth of Carcharinus (sample 15, Table 1). Fluorine is detectable in enameloid (top) and dentin (bottom).

random shapes dispersed between the bundles indicate diagenetic alterations (Fig. 3B).

Fig. 4 shows an EDX line scan across the fossilized shark tooth shown in Fig. 3. There is no significant gradient in the fluoride content. The average EDX intensities are $106 \pm 29$ for dentin and $99 \pm 46$ for enameloid (average \pm standard deviation). The correlation coefficients after linear regression are 0.197 for dentin and 0.019 for enameloid. Altogether, this indicates constant and identical fluoride concentrations in dentin and enameloid within the accuracy of the method and the statistical scatter within each tissue.

The individual EDX spectra of this tooth are shown in Fig. 5 with no discernible difference between enameloid and dentin.

Fig. 6 shows a representative X-ray powder diffractogram of this tooth. The only crystalline phase is apatite. A further analysis shows the presence of fluoroapatite. The lattice parameters and calculated fluorine content according to LeGeros/Suga et al. are given in Table 2.

Fig. 7 shows SEM images of the tooth of a fossil crocodile. The dentin-enamel junction is well preserved, and small individual crystallites oriented perpendicular to the tooth surface can be distinguished in the enamel, which is similar to the structure in recent crocodile teeth. ${ }^{23}$

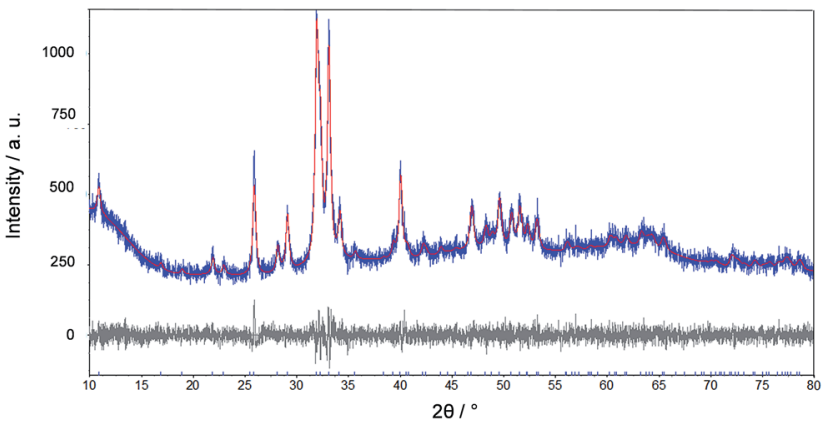

Fig. 6 Rietveld refinement of an X-ray powder diffraction measurement of a tooth of Carcharinus (sample 15, Table 1).
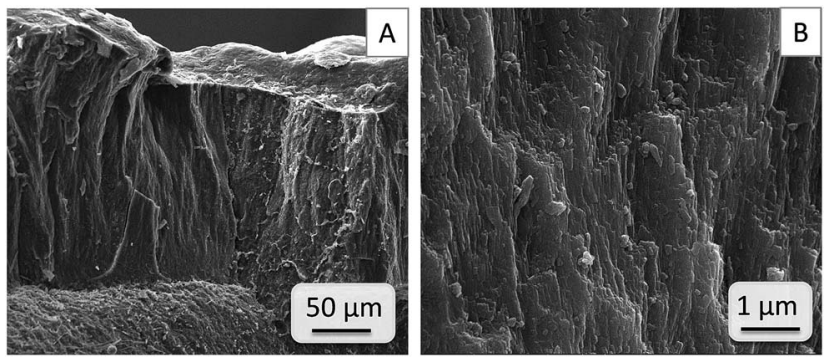

Fig. 7 SEM images of a tooth of Crocodylus, 3 million years old (sample 22, Table 1), showing the enamel-dentin junction (A), and an enamel close-up (B).
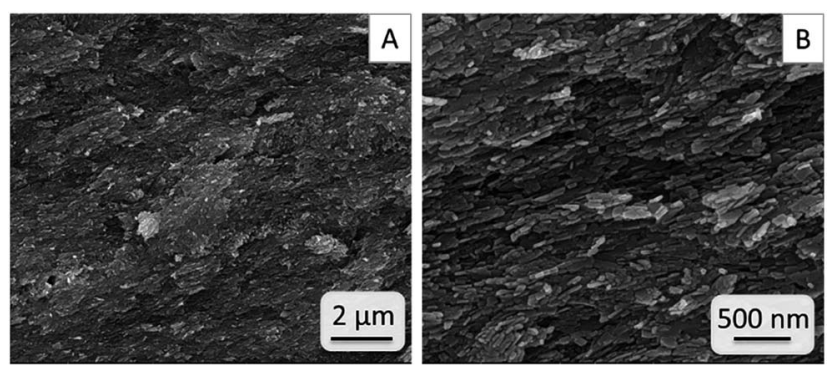

Fig. 8 SEM-images of the jawbone of Crocodylus, 3 million years old (sample 23, Table 1), showing the platelet nanostructure.

Fig. 8 shows SEM images of the jawbone of the same crocodile species. Partially, the fossil bone has preserved its original ultrastructure consisting of nanoscale platelet-like structures. However, the major part of the mineral phase is composed of fluoroapatite and calcite (see Table 2) according to X-ray powder diffraction and Rietveld refinement. The amount of fluoroapatite was higher in the substantia spongiosa, while the amount of calcite was higher in the substantia compacta. In both layers, high amounts of quartz were found, representing fossilisation artefacts.

Fig. 9 shows SEM images of a fossil sauropod dinosaur bone. The transition from substantia compacta (small pores) to substantia spongiosa (large pores) is well visible (Fig. 9A). Those pores are large enough to be filled with fossilisation artefacts. The EDX mapping shown in Fig. 10 indicates that the material present in the pores is most likely quartz, $\mathrm{SiO}_{2}$. 

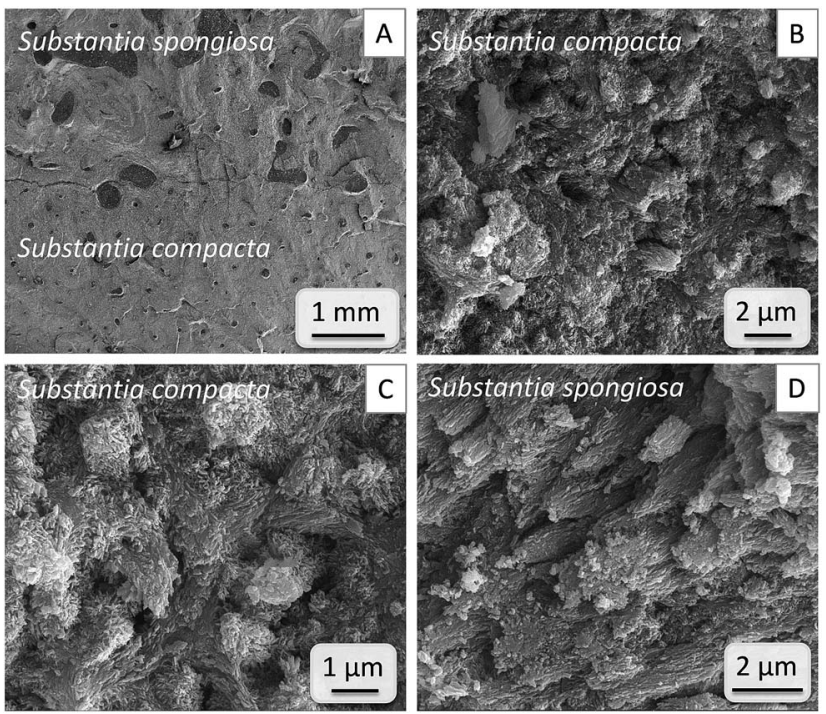

Fig. 9 SEM images of a sauropod dinosaur bone, 70 million years old (sample 4, Table 1). (A) shows the intersection of spongy and compact bone, (B) and (C) show close-ups of compact bone, and (D) shows a close-up of porous spongy bone.
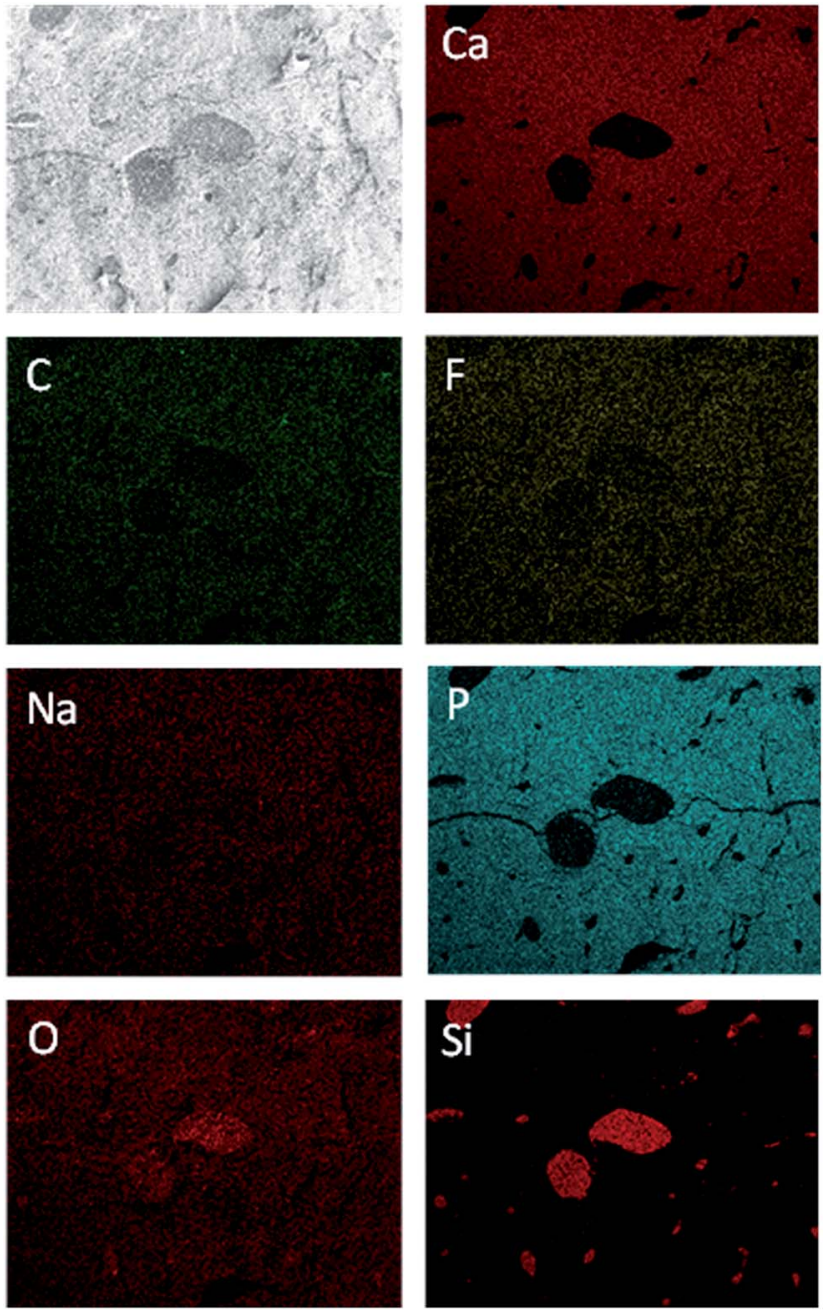

Fig. 10 EDX mapping of sauropod dinosaur bone (sample 4, Table 1), indicating quartz-filled pores.
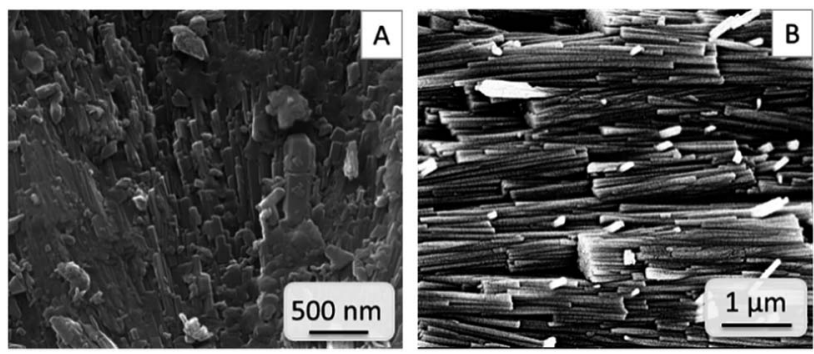

Fig. 11 SEM images of mammal tooth (whale ancestor, 50 million years old; sample 9, Table 1) (A), and a tooth of the shark Lamna sp. (8-10 million years old; sample 16, Table 1) (B). Both images show individual bundles in parallel direction in enamel (A) as well as in enameloid (B).

Fig. 11 shows SEM images of a middle Miocene mammal and another fossilised shark tooth. In the case of the raoellid mammal, individual small crystallites are arranged in parallel and oriented with their long axes perpendicular to the tooth surface, which is comparable to the ultrastructure of recent crocodile enamel $^{23}$ and to human enamel. ${ }^{24}$ The enameloid of teeth from the fossil Lamna species consists of thin and long crystallites arranged in parallel forming bundles that can also be found in recent shark tooth enameloid. ${ }^{9}$

\section{Conclusions}

The concept of this further work was to compare the fluoride content in fossil teeth and bones of extinct sharks, plesiosaurs, and dinosaurs as an extension of our earlier discussion ${ }^{\mathbf{1 0}}$ of fluoroapatite biomineralization vs. diagenetic fluoride incorporation. Since fluoridation in fossil teeth and bone is an inevitable chemical process, conclusions regarding the evolution of biomineralization in vertebrates based on chemical analysis of fossil remains should be avoided. Sharks use fluoroapatite to mineralize the enameloid of their teeth and do not have mineralized bones such as other vertebrates that use hydroxyapatite to mineralize their skeletons. As our results show the presence of high amounts of fluoroapatite in all investigated fossil plesiosaurs, mosasaurs, dinosaurs, crocodiles and mammals both in teeth and bones in contrast to all recent reptiles, birds and mammals, we conclude that their fluoride content is of diagenetic origin. Furthermore, our results indicate that the continuous diagenetic substitution of hydroxide by fluoride during fossilization is facilitated by the porosity present in the different morphological structures of both teeth and bone. The samples analysed in the present study came from silica- and carbonate-bearing rocks such as sandy limestones and pedogenic clays. This explains the presence of diagenetic minerals such as quartz, calcite, and francolite in the samples.

\section{Acknowledgements}

This work was supported by the Deutsche Forschungsgemeinschaft (DFG) to M. E. and D. R. within the 
priority program SPP 1420 . R. P. is supported by the Ministry of Earth Science by grant number MoES/P.O. (Geosci)/46/2015 and DST, PURSE. We thank Mrs Kerstin Brauner, Mrs Carola Fischer, and Mr Robin Meya for help with the sample preparation.

\section{References}

1 H. A. Lowenstam and S. Weiner, On biomineralization, Oxford University Press, New York, 1989.

2 R. Z. LeGeros, Prog. Cryst. Growth Charact., 1981, 4, 1-45.

3 S. Mann, Biomineralization, Oxford University Press, Oxford, 2001.

4 Handbook of Biomineralization, ed. E. Baeuerlein, P. Behrens and M. Epple, Wiley-VCH, Weinheim, 2007.

5 R. Z. LeGeros and S. Suga, Calcif. Tissue Int., 1980, 32, 169174.

6 I. J. Moeller, B. Melsen, S. J. Jensen and E. Kirkegaard, Arch. Oral Biol., 1975, 20, 797-802.

7 G. Daculsi and L. M. Kerebel, Arch. Oral Biol., 1980, 25, 145151.

8 J. Enax, O. Prymak, D. Raabe and M. Epple, J. Struct. Biol., 2012, 178, 290-299.

9 J. Enax, A. M. Janus, D. Raabe, M. Epple and H. O. Fabritius, Acta Biomater., 2014, 10, 3959-3968.

10 A. Luebke, J. Enax, K. Loza, O. Prymak, P. Gaengler, H. O. Fabritius, D. Raabe and M. Epple, RSC Adv., 2015, 5, 61612-61622.
11 M. de Renzi, E. Manzanares, M. D. Marin-Monfort and H. Botella, RSC Adv., 2016, 74384-74388.

12 S. F. Cook and R. F. Heizer, Am. J. Phys. Anthropol., 1959, 17, 109-115.

13 M. R. Goodrum and C. Olson, Br. J. Hist. Sci., 2009, 42, 95114.

14 J. Elorza, H. Astibia, X. Murelaga and X. Pereda-Suberbiola, Cretaceous Res., 1999, 20, 169-187.

15 R. Patnaik, Comptes Rendus Palevol, 2016, 15, 889-902.

16 H. P. Klug and L. E. Alexander, X-ray diffraction procedures for polycrystalline and amorphous materials, Wiley-Interscience, New York, 1974.

17 K. F. Downing and L. E. Park, Palaios, 1998, 13, 14-27.

18 G. H. McClellan, J. Geol. Soc., 1980, 137, 675-681.

19 J. M. McArthur, Geochim. Cosmochim. Acta, 1985, 49, 23-35.

20 J. C. Elliott, Rev. Mineral., 2002, 48, 427-453.

21 K. T. Hollocher, T. C. Hollocher and J. K. Rigby, Palaios, 2010, 25, 132-140.

22 C. N. G. Trueman, A. K. Behrensmeyer, N. Tuross and S. Weiner, J. Archaeol. Sci., 2004, 31, 721-739.

23 J. Enax, H. O. Fabritius, A. Rack, O. Prymak, D. Raabe and M. Epple, J. Struct. Biol., 2013, 184, 155-163.

24 M. F. Teaford, M. M. Smith and M. W. J. Ferguson, Development, function and evolution of teeth, Cambridge University Press, Cambridge, 2000. 